\title{
Aspectos econômicos e políticos determinantes da política social brasileira
}

\author{
Economic and political aspects of the brazilian social policy
}

\begin{abstract}
Maria Luiza Amaral RIZZOTTI ${ }^{1}$
Resumo: O caminho recente das políticas sociais brasileiras encontra dificuldades que devem ser avaliadas à luz do seu processo histórico e estrutural. O presente artigo tem a finalidade de retomar as reflexões sobre tais aspectos sob a égide das tradicionais funções do Estado moderno e das principais características do modelo do Estado Brasileiro. A pesquisa bibliográfica busca trilhar um caminho analítico a partir da tradição marxista, tanto no que concerne às explicações dos fundamentos do Estado, quanto na leitura da sociologia histórica brasileira.

Palavras-chave: Estado. Políticas Sociais. Aspectos Econômicos e Políticos. Sociedade Civil.

Abstract: The recent path of Brazilian social policies has met difficulties which should be assessed in the light of their structural and historical process. This article aims to resume the discussions on such issues under the auspices of the traditional functions of modern State and the main features of the model of the Brazilian State. The bibliographical research pursues an analytical path from the Marxist tradition, both with regard to explanations of the foundations of the State, as in reading the historical sociology.
\end{abstract}

Keywords: State. Social Policies. Economic and Political Aspects. Civil Society.

Submetido em: 10/4/2013. Aceito em: 16/6/2013.

\footnotetext{
${ }^{1}$ Assistente Social, doutora em Serviço Social e Política Social pela PUC/SP, professora associada da Universidade Estadual de Londrina (UEL), Brasil. E-mail: <marialuizarizzotti@gmail.com>.
}

Argumentum, Vitória (ES), v. 5, n.1, p. 165- 179, jan./jun. 2013. 


\section{Introdução}

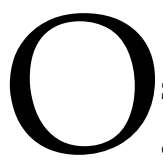
estudo da gestão de políticas sociais que pretende subsidiar análises referentes aos seus entraves e desafios deve ser pensado considerando o seu arcabouço teórico e histórico. Tais dimensões fundam-se e sofrem influência dos modelos econômicos, políticos e sociais adotados pelos Estados Nacionais, assim como se transformam a partir dos fundamentos legais e teóricos que lhes oferecem capacidades explicativas.

O estudo do tema aqui empreendido reserva alguns desafios que estão mesclados e influenciados pelo campo crítico de análise das políticas sociais com o objetivo de amalgamar a importante presença da relação entre Estado e sociedade civil no aprimoramento das políticas sociais e, por consequência, a extensão de sua capacidade protetiva de garantia de direitos.

Com isso a composição deste estudo perpassa fundamentos do Estado Brasileiro que têm influência sobre as políticas sociais, conjugando conteúdos na perspectiva histórica e conceitual que permitam a sistematização de conhecimentos capazes de garantir uma análise crítica do tema. Perpassam estes conteúdos aspectos referentes à relação do modelo capitalista de produção e a posição do Estado burguês na composição das lutas sociais que tematizaram as proposições de políticas sociais.

As relações condicionantes entre o Estado Moderno e a produção capitalista foram reiteradamente abordadas pela tradição marxista. Já nas obras políticas de Marx em O Capital - a despeito do ponto no qual se interrompe esta última obra - a análise aponta quatro funções básicas que desempenha o Estado contemporâneo na produção capitalista.

Em primeiro lugar, o Estado desempenha a função de capitalista coletivo ideal, segundo a qual atua na criação de condições materiais genéricas para a produção (isto é, a infraestrutura necessária ao desenvolvimento do capital em seus diferentes ramos - energia, transporte, comunicações, etc.). Essa função inicial do Estado pode ser constatada desde o período da acumulação primitiva do capital e, após a existência de um curto período de capitalismo concorrencial, ganha ênfase novamente com o surgimento das condições monopolistas de produção.

Em segundo lugar, o Estado contemporâneo desempenha na produção a função de árbitro, através da criação e sustentação do sistema geral de leis, destinado a regulamentar as relações sociais fundadas na e destinadas à produção de mercadorias.

Subsidiariamente, uma terceira função agrega-se a esta última: o Estado regulamenta as relações entre capital e trabalho assalariado, intervindo desde um ponto exterior no conflito de classes e completando o conjunto de condições internas para a produção.

Finalmente, uma última, mas não menos importante função consiste na política comercial externa desempenhada 
pelos Estados contemporâneos, através da qual logram prover as condições necessárias à expansão do capital nacional total no mercado internacional.

Segundo a análise marxiana, portanto, o Estado realiza sua função estratégica ao prover as condições necessárias e suficientes à formação do capital social conjunto, propiciando a subsunção do capital comercial ao industrial e das formas não capitalistas de produção à forma mercadoria. Nesse sentido é que pode ser definido como instrumento de opressão de classe sobre classe, através do qual a burguesia impõe um modo específico de dominação política e de exploração econômica na era capitalista.

O resultado essencial desse seu papel é que se produz a socialização dos custos de reprodução da força de trabalho e do capital em geral, permanecendo subordinada à política econômica do Estado (em sua forma monetária, fiscal ou social) e aos setores monopolistas e competitivos da produção capitalista. Nesse processo, cujo ponto extremo pode ser localizado na constituição e evolução das formas do capital financeiro, duas lógicas antagônicas coexistem: a do capital, consubstanciada no caráter quantitativo do valor e na finalidade de produção de mercadorias e a do Estado, expressa no caráter qualitativo das diferentes demandas públicas e na finalidade de produção de serviços.

A emergência do estágio monopolista de produção e da subsequente fase da acumulação flexível de capital acentu- aram, ainda mais, as funções do aparelho político do Estado no processo de produção capitalista. Não obstante, o papel desempenhado na realização da acumulação primitiva do capital, as atribuições do Estado durante o processo normal de produção capitalista concorrencial deveriam resumir-se essencialmente à função de árbitro dos contratos e garantidor da forma mercadoria e de suas manifestações na produção. Mas as transformações ocorridas no modo de produção capitalista durante o último século tornaram essa função por si só insuficiente, ocasionando uma alteração-chave, que consistiu na conversão do Estado de árbitro da economia em interventor ativo no processo de acumulação do capital.

Paralelamente, essa nova condição provoca também transformações nas instituições políticas de nossa época, sintetizadas no esvaziamento do poder legislativo e das formas de representação que o Estado incorpora em favor de uma organização corporativa do poder e na transição da fórmula clássica de lei geral para uma intervenção legislativa ad hoc na vida social.

Com efeito, a organização e desenvolvimento do Estado de Bem-Estar no mundo ocidental expressa genuinamente essas transformações do aparelho político do Estado na sociedade capitalista contemporânea. Como resposta capitalista à crise econômica e social evidenciada com o episódio da grande depressão americana e como reação política ao avanço do socialismo ocorrido desde o período entre guerras, o advento do Estado de Bem-Estar 
criou para as sociedades capitalistas (nas quais se desenvolveu) uma nova realidade política, a saber: a de que a legitimidade do poder do Estado, antes residente na forma racional-legal da organização política democrática, encontrar-se-ia desde então condicionada ao grau de eficácia da ação do Estado na resposta à crise capitalista, que de um lado expressava-se pelo perigo da estagnação nas economias de mercado, de outro tomava a forma de aberta exclusão social.

Se, ademais, considerarmos o caráter de clara dependência fiscal do aparelho político de Estado em relação à economia capitalista privada - dependência que se configura em sua forma cabal na contradição entre a natureza do objeto fiscal e os vínculos de uma economia concorrencial de um lado e, de outro, no incremento incontrolável (do ponto de vista das instâncias internas do aparelho do Estado) da demanda de despesa pública - podemos então apreciar com relativa precisão o processo pelo qual a legitimidade do poder político resulta corroída nas novas configurações da sociedade contemporânea.

À mudança nas formas de legitimidade do poder corresponde uma profunda transformação do aparelho político do Estado. A questão central, aqui, consiste na frágil possibilidade de coexistência das formas clássicas do Estado de Direito com os novos papéis desempenhados pelo Estado de BemEstar Social. E isto porque de um lado, não podem ser livremente compatibilizados, sem prejuízo para qualquer dos lados, os direitos fundamentais de liberdade pessoal, política e econômica, constituídos a partir da ideologia liberal e da distribuição da riqueza social produzida. De outro, extingue-se a cisão das esferas pública e privada ${ }^{2}$ originada da separação entre sociedade e Estado com a constituição daqueles direitos fundamentais, fundindo-se ambas numa nova realidade, através da qual se processa a reprodução social capitalista.

Desse modo, é nosso objetivo, ao empreendermos essa reflexão, situar no universo de transformações políticas e econômicas do capitalismo contemporâneo e, nos condicionantes recíprocos que deles emergem, a análise das políticas sociais no Brasil. Com as atuais mudanças no mundo do trabalho, um novo componente surge na relação das políticas sociais geradas pelo fundo público e reprodução da força de trabalho. A relação do capital com o fundo público direciona-se mais para o financiamento do avanço tecnológico e menos para a reposição da força de trabalho. Além disso, os modelos de flexibilização dos contratos do trabalho vivo mantém sua suscetibilidade à apropriação do capital, agora não ape-

\footnotetext{
${ }^{2}$ Essa cisão entre as esferas tem parte de sua explicação pautada no posicionamento de Anderson (1992). "Por um lado, funções públicas hoje normalmente atribuídas ao Estado - educação, bem-estar social, saúde, comunicações estão localizadas no espaço da sociedade civil. Por outro lado, as associações corporativas originárias da sociedade civil estão inseridas na estrutura política do Estado, como as unidades eletivas da Assembleia dos Estados" (ANDERSON, 1992, p. 21).
} 
nas com centralidade na força física, mas multidimensionada e com capacidade de plasmar a obrigatoriedade de trabalhar para viver ao mesmo tempo em todas as demais dimensões da vida estão absortas pelo trabalho. Esse cenário imprime novas exigências do Estado no que concerne à regulação e ampliação do modelo de proteção social contributivo e não contributivo.

Em economias onde o recurso público tinha de ser utilizado para a reprodução do contingente total da força de trabalho, isso não aparecia para o capital como um gasto elevado. A partir do momento em que os ganhos de produtividade do trabalho, baseados no desenvolvimento tecnológico e nas novas técnicas de produção, possibilitam liberar grande parcela da força de trabalho, tornando-as desnecessárias para a manutenção de ciclos de reprodução do capital, os gastos em políticas sociais aparecem ao capital como desnecessários, já que perderam sua função estratégica na economia capitalista.

Nos casos dos países subdesenvolvidos, Cignolli (1985) salienta que desde o princípio a tecnologia utilizada caracterizou-se como poupadora de mão de obra e, portanto, inexistiu o momento de ampla reprodução da força de trabalho. Neste sentido, para estes países, aos olhos do capital sempre apareceu como um gasto excessivo.

Segundo Oliveira (1988), os verdadeiros motivos da crise do Estado de BemEstar Social podem estar associados à ultrapassagem dos limites nacionais da produção e à manutenção destes mes- mos limites no financiamento público de reprodução da mão de obra. Enquanto os capitais convertem-se em transnacionais, os custos de reprodução da força de trabalho permanecem nacionais, no sentido de serem bancados pelo fundo público estatal.

\section{A trajetória brasileira e sua influência nas políticas sociais}

As explicações referentes à política social brasileira não podem e não devem ser fracionadas, sobretudo quanto a determinantes econômicas, políticas e ideológicas, se elas se constituem como partes de uma mesma organicidade explicativa. Neste sentido, faz-se necessário articular temas como o desenvolvimento do capitalismo no Brasil, a constituição do Estado brasileiro, a participação da sociedade civil e a influência do pensamento social brasileiro nas explicações para a questão social no Brasil.

O conjunto destes aspectos só pode ser compreendido e constituído numa totalidade, se articulados do ponto de vista da crítica e da história. Portanto, torna-se indispensável a discussão sobre o desenvolvimento econômico e as características do Estado brasileiro, tendo como elemento central da questão social no Brasil e da relação sociedade civil e Estado, as especificidades da burguesia nacional delineadas pela estrutura econômica dependente.

A particularidade da classe burguesa brasileira está associada ao modelo econômico que se desenvolve sob as marcas do neocolonialismo e das fortes 
determinações do capital externo. A análise do processo de desenvolvimento econômico é feita através da passagem do padrão colonial de crescimento econômico para o padrão de desenvolvimento capitalista, o que não ocorreu linearmente, mas configurou-se muito mais na passagem do colonial para o neocolonial e, consequentemente, para o capitalismo dependente.

O período colonial brasileiro sofreu estagnação econômica e foi demarcado pelo contexto socioeconômico e político, sobretudo porque lhe impunha a característica de uma sociedade colonial. Um dos fortes aspectos desta economia é a sua tendência para a exportação de produtos naturais - açúcar, tabaco, posteriormente ouro, diamante, etc. (PRADO JÚNIOR, 1987).

A formação social é determinada de fora para dentro, e tudo deveria convergir para favorecer o mercado externo, desde as especulações no campo produtivo e financeiro até o recrutamento de mão de obra de índios e negros. O rompimento com este estatuto colonial e a criação de um Estado nacional se constituiu a condição primordial para mudanças na ordem econômica e social.

Esse processo que demarcou a ruptura com o regime colonial, apesar de imbuído do espírito burguês, não tinha em pauta a defesa de direitos sociais ou a luta pela cidadania, mas somente livrar-se dos grilhões da sociedade colonial marcada pela escravidão e pelo patrimonialismo.
Segundo Fernandes (1975), duas etapas foram vividas na sociedade brasileira:

$\left.1^{\circ}\right)$ a ruptura da homogeneidade da aristocracia agrária; $2^{\circ}$ ) o aparecimento de novos tipos de agentes econômicos sob a pressão da divisão do trabalho em escala local, regional ou nacional (FERNANDES, 1975, p.27).

As origens agrárias brasileiras impediram a noção de competitividade, implicando na inexistência de um liberalismo genuíno. Este país apresentou-se como um Estado oligárquico que vai persistir até a revolução de 1930.

A constituição da burguesia nacional nos interessa, sobretudo quanto ao fato de que a classe dominante brasileira, desde sua origem, nunca teve em seu ideário a luta e a garantia de cidadania e de democracia, pensada sob a luz de extensão de direitos sociais. Ao discutir o surgimento da burguesia nacional, Fernandes (1975) faz referência ao movimento abolicionista, localizando-o, sobretudo, como núcleos nos espaços urbanos:

Por fim, destes núcleos é que partiu o impulso que transformaria o antiescravismo e o abolicionismo numa revolução social dos brancos: combatia-se assim não a escravidão em si mesma, porém o que ela representava como anomalia, numa sociedade que extinguira o estatuto colonial, pretendia organizar-se como nação e procurava, por todos os meios, expandir internamente a economia de mercado (FERNANDES, 1975, p.19).

O envolvimento da classe burguesa pelo fim do escravismo teve sua motivação na criação de condições políticas 
para a expansão da economia nacional e internacional, portanto, não se tratava de uma conquista pelo ideário abolicionista.

A burguesia nacional sustentou-se e pôde adequar-se às novas demandas econômicas por sua capacidade de readaptar-se estruturalmente. Esse processo de readequação que lhe permitiu superar a própria crise do poder burguês, só foi possível por três aspectos explicativos: a articulação com o mercado externo, a organização política própria e o favorecimento do Estado na manutenção do poderio econômico (FERNANDES, 1975). Destas três, a última nos interessa mais de perto, por tratar-se do posicionamento do Estado em face da manutenção da ordem social vigente.

A possibilidade de converter o Estado em um eixo político de recomposição do poder econômico, social e político da burguesia, estabelecendo-se uma conexão direta entre dominação de classe, e livre utilização, pela burguesia, do poder político estatal daí resultante (FERNANDES, 1975, p.264).

As consequências disto são: a inexpressividade de forças antagônicas com perspectivas de organizar-se sob a lógica de contraposição política e revolucionária e um rígido controle sob o processo de organização das classes populares.

Características como a ausência de um projeto político nacional, fortalecimento externo das oligarquias regionais na organização política e a repressão às formas de participação popular estão determinadas pela forma como o Esta- do brasileiro organizou-se sob forte influência de uma burguesia frágil (sob a ótica de outros países), porém capaz de imprimir internamente uma força reguladora em relação aos interesses de outras classes sociais. A questão da repressão ou do enquadramento e regulação é colocada no âmbito do controle senhorial:

Resguardava-se a sociedade do corrosivo espírito burguês, fortalecendo-se os laços que prendiam os homens aos seus níveis sociais aos correspondentes códigos de honra, e ao mito que o Brasil é ingovernável sem a versão autocráticopaternalista do despotismo esclarecido (FERNANDES, 1975, p.165).

A história brasileira foi demarcada pela separação entre a sociedade civil e o Estado. Esta separação tem engenhosa ação da classe dominante burguesa, que buscou identificar sua luta com o "direito natural revolucionário" (FERNANDES, 1975, p.302). E, também, com a capacidade de relacionar o conceito de nação a algo distante e abstrato do cotidiano da vida social, exceto apenas quando esta deve se interpor a favor de ideário da minoria.

[...] a dominação burguesa não é só uma força socioeconômica espontânea e uma força política regulativa. Ela polariza politicamente toda a rede de ação auto defensiva e repressiva, percorrida pelas instituições ligadas ao poder burguês, da empresa ao Estado, dando origem a uma formidável superestrutura de opressão e de bloqueio, a qual converte, relativamente, a própria dominação burguesa na única fonte de poder legítimo (FERNANDES, 1975, p.303).

Ao apontar as características da burguesia nacional, o autor coloca que sua

Argumentum, Vitória (ES), v. 5, n.1, p. 165- 179, jan./jun. 2013 
identidade com a modernidade e civilização era equacionada por interesses particulares e, quando reclamado seu posicionamento a favor de outros grupos, respondia de forma conservadora e reacionária:

[...] que nos sirva de exemplo o tratamento das greves operárias da década de 1910, em São Paulo, com puras questões de polícia; ou quase meio século depois a repressão às aspirações democráticas das massas (FERNANDES, 1975, p.206) ${ }^{3}$.

3 A história oficial brasileira reserva pouco espaço para a ação dos movimentos sociais que lutaram e expressaram necessidade de mudanças. Também fala-se pouco na forma de tratamento que as classes dominantes dispensavam a estas manifestações, através de seu aparato repressivo. Apenas como exemplo vale lembrar as lutas dos operários no período da velha república que, apesar de não ter desenvolvido formas mais avançadas de organização, foram fortemente reprimidas. A história oficial brasileira reserva pouco espaço para a ação dos movimentos sociais que lutaram e expressaram necessidade de mudanças. Também falase pouco na forma de tratamento que as classes dominantes dispensavam a estas manifestações, através de seu aparato repressivo. Apenas como exemplo vale lembrar as lutas dos operários no período da velha república que, apesar de não ter desenvolvido formas mais avançadas de organização, foram fortemente reprimidas. Del Roio (1986), em seu livro sobre a história dos movimentos sociais no Brasil, coloca "Os primeiros anos do século assistiram a uma série de paralisações do proletariado, buscando melhores salários e, sobretudo, uma redução da longuíssima jornada de trabalho. A parede dos tecelões na capital contou com 25.000 adesões. Um número enorme para a época! Seguiram-se os sapateiros, os gráficos, os chapeleiros e os carroceiros(bloqueando a circulação). Também a marinha mercante parou em protesto contra o recrutamento forçado para a marinha de guerra, havendo embates
Cabe, porém, lembrar que o mesmo autor considera a burguesia brasileira como fruto de uma transmutação da oligarquia, chamada de nova aristocracia, vulnerável e manipulável pela oligarquia conservadora.

A ênfase na caracterização nacional das classes dominantes justifica-se pela intrínseca relação entre esta e o desenvolvimento capitalista. No caso brasileiro, o comportamento particularista dos que conduziam o processo permitiu:

[...] a continuidade da dominação imperialista externa; -a permanente exclusão (total e parcial) do grosso da população não possuidora do mercado e do sistema de produção especificamente capitalista; e dinamismos econômicos débeis e oscilantes, aparentemente insuficientes para alimentar a universalização efetiva (e não apenas legal) do trabalho livre, a integração nacional do mercado interno e do sistema de produção em bases genuinamente capitalistas, e a industrialização autônoma (FERNANDES, 1975, p.223).

O potencial de luta, ou focos de tensão como são chamados por Florestan Fernandes, era transmutado em relações de obediência e dever com os homens entre si e destes com seus senhores. Os instrumentos de cooptação eram utilizados sob a forma de garantia de poder, riqueza e prestígio.

A competição continha alguma significação estrutural e funcional apenas por-

em todos os portos. Entre derrotas e vitórias parciais, quase sempre coibido o movimento avançava" (DEL ROIO, 1986, p.41). 
que a dominação patrimonialistatradicional expunha os parentelos, como grupos ou através de seus chefes, uma constante emulação na luta pela preservação ou pelo aumento de riqueza, de prestígio social e poder. Mas ela não se manifestava como um processo diferenciado e social percebido ou valorizado como tal. Ao contrário constituía um componente estrutural e dinâmico das obrigações sociais que ligavam os homens entre si e ao senhor... através das tradições, do dever de mando ou de obediência e da solidariedade moral (FERNANDES, 1975, p.152).

O autor está preocupado com a passagem para uma nova ordem competitiva no Brasil e, no cerne desta discussão, está a tradição patrimonialista, na qual o equilíbrio social se faz por solidariedade gestada sob formas autocráticas. Em sua análise, complementa as explicações pondo em pauta não apenas questões ligadas à identidade nacional, mas especificamente á relação entre as características particulares dos estamentos ou classes, que detinham o poder na condução do desenvolvimento capitalista no Brasil.

Além disto, apontou as suas consequências como determinantes para a existência de um sistema econômico dependente, no qual a exclusão social passou a ser uma marca que se perpetuou em todas as suas etapas. Agregase a esta marca, a repressão aos movimentos populares que estampavam a necessidade de medidas governamentais nesta área. $\mathrm{O}$ estudo da configuração econômica e política de tal forma imbricada, como apresenta Fernandes (1975), é difícil de ser superado. Porém vale fazer menção aos contornos políti- cos que demarcaram a história do Brasil.

Tais contornos foram analisados por pesquisadores diferentes sob marcos também diferenciados. Ianni (1971) realiza uma análise a partir das rupturas nas estruturas políticas e econômicas. Para o autor, no período entre a Primeira Guerra Mundial e o Golpe de Estado de 1964, ocorreram fatos que demarcam tanto as rupturas, quanto as transformações institucionais importantes. Das citadas por Ianni (1971), cabe destacar a relação entre o aceleramento da indústria com uma política de massas. As décadas anteriores ao Golpe Militar foram marcadas por forte populismo e, ao mesmo tempo, foram se organizando os partidos políticos de esquerda:

Em consequência a nova organização do poder, característica da ação política, floresceram atividades políticas e culturais, criando uma cultura urbana diferente e mais autenticamente nacional. Ao mesmo tempo, desenvolveram contradições econômicas, políticas e sociais e criaram organizações políticas de esquerda (IANNI, 1971, p.9).

No período posterior ao governo Getúlio Vargas, nos anos de 1956 a 1960, governado por Juscelino Kubitschek, houve uma junção de interesses econômicos dominados pelos ditames do capital externo com a manutenção de uma política de massas. Não mais de conotação nacional, este período foi importante para o fim da proposta de desenvolvimento de caráter nacionalista. Naturalmente a passagem de um projeto que invocasse o nacionalismo 
foi sendo substituído em função de acontecimentos no campo internacional.

Segundo Ianni (1971), as principais causas foram: a possibilidade de o Brasil ser independente e ter ascendência sobre os países da América Latina e a liderança norte americana sobre $\mathrm{o}$ mundo capitalista e, ainda, os acordos internacionais definirem sua liderança exclusiva sob a América Latina. Do ponto de vista da política interna, um aspecto que punha em risco a segurança do poderio econômico, foi a ascensão de movimentos de esquerda que ameaçavam a ordem e o poder burguês. A participação popular após a década de 1940 foi se modificando motivada pela luta política que exigiu, tanto da direita como da esquerda, novas estratégias de luta pelo poder:

\begin{abstract}
Embora o populismo ainda perdurasse muito além de 1945, aceitando as pressões populares e manipulando seus anseios em nome da ordem instituída, parece claro que as alianças partidárias experimentavam o impacto causado pela crescente força das reivindicações dos trabalhadores (VIEIRA, 1987, p.20). ${ }^{4}$
\end{abstract}

A relação entre Estado e sociedade civil foi tomando contornos diferentes numa mescla de ditames econômicos e políticos externos, mudanças nos interesses da economia interna, sobretudo com a passagem do modelo agroexportador para o urbano industrial, a mul-

4 No livro Estado e Miséria Social no Brasil de Getúlio a Geisel, Evaldo Vieira faz importantes associações entre aspectos econômicos e políticos no Brasil e a instituição e implementação de políticas sociais. tiplicação de instauração e ações de grupos políticos de esquerda e a organização dos trabalhadores urbanos. Desta forma, puderam-se ver no cenário nacional lutas políticas associadas a projetos de modernização exigidos pelo desenvolvimento urbano industrial e a constituição de um proletariado urbano que passa a apresentar, de forma mais pontual, suas reivindicações por melhores condições de vida e trabalho.

O Estado Militar, que teve início em abril de 1964, buscou a estabilização econômica com prevalência no investimento urbano industrial. Com ele, implantou-se um regime de repressão que acabou por desagregar o nacional populismo que vigia até então. A análise de Celso Furtado recolocada por Cardoso (1993) indica a reação dos atores políticos de então, sobretudo, das classes médias que passaram a desenvolver as seguintes ações:

a) luta pela retomada da democracia formal; b) tentativas, a partir da juventude, de mobilização das massas especialmente as rurais, para contrapor-se ao Estado Militar; c) infiltração do estamento militar por ideologias favoráveis ao desenvolvimento autenticamente nacional, ideologias estas que também encontram base em setores de classe média (CARDOSO, 1993, p. 59).

Neste sentido, não apenas as formas de repressão e controle do Estado deram conta de conter as pressões, foi necessária a inclusão de algumas forças sociais tais como: as classes médias e alguns setores das Forças Armadas. Caminharam de forma plasmada o proje- 
to econômico dependente associado ${ }^{5} \mathrm{e}$ o processo político. $\mathrm{O}$ modelo político por um lado, associava as classes médias com o projeto de um desenvolvimentismo industrial dependente e, por outro, um sistema repressor que desativou organizações de classe com forte característica de uma sociedade politicamente fechada. Os instrumentos para isso, além da repressão militar, foram a centralização administrativa e a burocratização do Estado.

A abertura política e a reconstrução do Estado de Direito traz à tona a discussão da relação entre Estado e sociedade civil, agora dentro das conformações da democracia. As características que este novo momento político apresenta, estão diretamente associadas a outros momentos de vivência democrática no país.

Nas décadas de 1940 e 1950 a defesa da democracia tinha em seu cerne a preocupação de incorporar a classe trabalhadora ao processo político com o objetivo de controlar as pressões por ela exercidas sobre o Estado.

O período do populismo apresentou uma forma de relação entre o Estado e a população. A marca deste período era o trato direto com as lideranças populistas e as reivindicações de massa. Weffort (1978), ao analisar o proces-

5 Ianni (1971) no livro O Colapso do Populismo no Brasi, ao falar sobre os modelos de desenvolvimento do Brasil denomina-os de exportador, substituição, associado . O modelo associado refere-se ao período da ditadura militar no qual há a combinação de empresas brasileiras e estrangeiras. so de democratização no Brasil, coloca a década de 1940 como o período em que a democracia rompe com o simples formalismo e vai tomando os contornos de uma participação popular efetiva.

O mesmo autor, porém, aponta para os limites desta forma de organização, ressaltando o fato de o Estado se apresentar multifacetado e emaranhado de compromissos com os vários segmentos tanto da direita quanto da esquerda. Um dos problemas deste tipo de organização ou desorganização participativa é que as massas ficam à mercê de manipulações de cunho clientelista, semelhantes às utilizadas pelo coronelismo, também difundidas nos espaços urbanos.

Para Furtado (1979), esta prática democrática pode ter sido determinada tanto pelo ritmo lento pelo qual se instituiu a democracia formal no Brasil, quanto pelas resistências em torno de uma organização, em que as chamadas massas populares pudessem expressar seus interesses.

A defesa da democracia passou a ser bandeira dos mais diversos grupos intelectuais $^{6}$ e da classe dominante. Para estes últimos, a democracia significava a possibilidade de melhorar as

\footnotetext{
6 A relação dos intelectuais e a democracia foi tratado por Pécaut em seu livro Os intelectuais $e$ a Política no Brasil: entre o povo e a nação de 1990. Ao analisar os anos 54-64 aponta para a pouca participação política partidária deste segmento e a defesa da democracia real, identificando o povo à nação.
} 
relações econômicas de domínio externo, portanto passaram a compor grupos organizados como a Ação Democrática Popular (ADEP) (RESENDE, 1996).

Alguns grupos de esquerda entendiam que o cerne da luta deveria ser a possibilidade de a população constituir-se em sujeitos políticos de transformação e a questão da democracia não compunha estes interesses, ao contrário, significava aspectos a serem superados para a constituição de um novo projeto nacional. A democracia passou a ser utilizada pela direita como instrumento de desarticulação e enfrentamento dos grupos opositores, chegando ao final da década de 1960 com proposição oposta à ideia de transformação social:

Por um lado, o regime militar e seu grupo de poder insistiam em que suas medidas ditatoriais eram a expressão da verdadeira democracia que convinha ao país. Por outro, parte da esquerda mostrava-se empenhada numa transformação revolucionária e não via com bons olhos qualquer menção à palavra democracia (RESENDE, 1996, p.36).

A construção de uma sociedade democrática, que historicamente sempre foi frágil no Brasil, demandaria a participação efetiva da classe trabalhadora no processo político. Isto significaria a emergência dos movimentos sociais o que foi intensificado a partir do final da década de 1970 e nos anos 1980. Sader (1988) destaca a importância dos movimentos sociais organizados.
O destaque não foi apenas para a diversidade de sujeitos políticos que permitiu uma característica própria para o fim da ditadura militar, mas, sobretudo a politização das lutas que foram de inicio mais pontuais como o movimento sindical, as comunidades eclesiais de base, as associações de moradores e foram se transformando em lutas pela reconstrução do Estado de Direito no Brasil.?

Se por um lado, o processo que deu fim ao autoritarismo militar pode ser visto como aceitação de uma proposta de negociação deste regime, já desgastado e internacionalmente criticado pelo desrespeito aos direitos humanos, gerando uma liberação controlada e negociada dentro do próprio Estado, por outro lado, a importante reação da sociedade civil organizada, mobilizando suas forças adquiriu capacidade de resistir ao autoritarismo. Neste sentido, a abertura democrática significou um movimento dialético de confronto e correlação de forças.

Por se tratar de um processo de lutas e conquistas, a democracia no Brasil foi suscitando adjetivações como participativa, democracia como ação política, democracia social, indicando a necessidade de articular as diversas dimensões institucionais, econômicas e políticas.

7 Sader (1988) em seu livro Quando os novos atores entram em cena cumpre um papel importante em delinear a participação dos movimentos sociais no processo de redemocratização do Brasil. 
Estas dimensões estão postas por Chauí (1997) ao discutir as condições sociais para a democracia. Mais do que a defesa da liberdade (bandeira dos liberais) ou da igualdade (bandeira das esquerdas) a democracia deve ser entendida como uma forma de vida.

Se, na tradição do pensamento democrático, democracia significa: a) igualdade, b) soberania popular, c) preenchimento das exigências constitucionais, d) reconhecimento da maioria e dos direitos da minoria, e) liberdade, torna-se óbvia a fragilidade democrática no capitalismo (CHAUÍ, 1997, p.141).

Segundo a autora, deve-se acrescentar a esta discussão pendular entre a igualdade e a liberdade, a questão da exploração de classe e o papel do Estado nela, o que necessariamente, remeteria a pensar a alienação e o Poder.

Três sujeitos estão postos nesta discussão: o Estado, a sociedade civil e a sociedade política, cujo caminho para a democracia seria a possibilidade de uma atuação rumo à hegemonia das classes populares e à "[...] vida social como coisa pública" (CHAUÍ, 1997, p.183). Está implícita nesta colocação a concepção de Estado que reconhece a correlação de forças expressadas pelas lutas das minorias e pelos movimentos mais amplos e populares, de forma a superar o modelo de grupos de pressão que tinha vigorado até então no Brasil.

\section{Conclusão}

A reflexão sobre das políticas sociais não se circunscreve apenas ao campo da economia ou da política, mas à in- ter-relação entre ambos. Percebe-se, porém, a dominação dos interesses econômicos. A reversão desta tendência dependeria de uma recolocação nas agendas políticas da questão das políticas sociais, diretamente relacionadas com a sobrevivência da democracia. A esse respeito, Kühn (1971) coloca que, nos países nos quais se tem maior acesso aos bens de consumo tem-se maior participação política, e que o inverso é verdadeiro, ou seja, maior participação política dá maior condição de defender uma sociedade mais igualitária.

Além disso, esta discussão pressupõe a concepção de um Estado que suporta a correlação de forças e a necessidade da conquista de hegemonia através da ação da sociedade civil, considerando a organização política dos vários grupos sociais. Dá-se neste contexto a discussão dos graus de consciência (econômico-corporativo, a solidariedade entre os membros de um grupo social e o grau que supera o círculo corporativo e incorpora interesses de grupos subordinados). Esta participação é possível por haver reivindicações e até mesmo reformas, mas sem alterações na estrutura do Estado (GRAMSCI, 1991).

O estudo das políticas sociais, mais especificamente daquelas resultantes da relação Estado e sociedade civil, recolocou o tema do Estado brasileiro aqui posto de forma sucinta apenas para demarcar sua constituição econômica e política. Se por um lado, a política social é uma invenção do modo capitalista de produção e do governo liberal, por outro, a história nos 
mostra a necessidade de existirem sujeitos sociais que engendrem lutas e conquistas para a constituição de direitos sociais.

No caso brasileiro foi necessário articular a luta por liberdades democráticas e o aprimoramento de direitos políticos com a garantia de direitos sociais. Neste pequeno estudo, foi nossa intenção explicitar o peso da história e do modelo brasileiro que, muito embora iluminem as reflexões atuais sobre as dificuldades de mudanças no plano político-ideológico e no cotidiano da gestão das novas proposições, também permitem coadunar as explicações sobre as possibilidades de limites de rompimento com as antigas práticas e proposições.

\section{Referências}

ANDERSON, P. O fim da história: de Hegel a Fukuyama. Rio de Janeiro: Jorge Zahar Editor, 1992.

CARDOSO, Fernando H. O modelo político brasileiro. 5. ed. Rio de Janeiro: Bertrand Brasil, 1993.

CHAUÍ, M. Cultura e democracia. 7. ed. São Paulo: Cortez, 1997.

CIGNOLLI, A. Estado e força de trabalho: introdução à política social no Brasil. São Paulo: Brasiliense, 1985.

DEL ROIO, J. L. Movimentos populares no Brasil. São Paulo, Global, 1986. (Coleção O Que Todo Cidadão Precisa Saber Sobre).
FERNANDES, F. A revolução burguesa no Brasil: ensaio de interpretação sociológica. Rio de Janeiro: Zahar, 1975.

FURTADO, C. Brasil: da república oligárquica ao Estado militar. Rio de Janeiro: Paz e Terra, 1979. (Brasil Tempos Modernos).

GRAMSCI, A. Maquiavel, a política e o Estado moderno. 8. ed. Rio de Janeiro: Civilização Brasileira, 1991.

\section{IANNI, O. O colapso do populismo} no Brasil. 2. ed. Rio de Janeiro: Civilização Brasileira, 1971.

KÜHN, Reinhard. El liberalismo. In: ABENDROTH, W.; LENK, K. Introducción a la ciencia política. Barcelona: Anagrama, 1971.

OLIVEIRA, Francisco. O surgimento do antivalor: capital, força de trabalho e fundo público. Revista Novos Estudos Cebrap, São Paulo, n. 22, p. 8-28, out./nov. 1988.

PÉCAUT, Daniel. Os intelectuais e a política no Brasil: entre o povo e a nação. São Paulo: Ática, 1990.

PRADO JÚNIOR, C. Formação do Brasil contemporâneo. 20. ed. São Paulo: Brasiliense, 1987.

RESENDE, Maria José. Democracia no Brasil: elementos norteadores do debate desenvolvido na segunda metade do século XX. Revista Mediações, Londrina, v. 1, n. 2, dez. 1996. 
SADER, E. Quando os novos personagens entram em cena: experiências e lutas dos trabalhadores da Grande São Paulo - 1970-1980. Rio de Janeiro: Paz e Terra, 1988.

WEFFORT, F. O Populismo na política brasileira. Rio de Janeiro: Paz e Terra, 1978.

VIEIRA, E. Amaro. Estado e miséria social no Brasil: de Getúlio a Geisel. 3. ed. São Paulo, Cortez, 1987. 